\title{
Fielding emotions: introduction
}

By Ingie Hovland (SOAS, University of London)

\section{What is the function of emotions in the socio-cultural anthropological research process?}

Emotions are inextricably tied up in our anthropological research and writing - in our apprehensive anticipation of the field, our feelings of helplessness once there, our anger at 'informants', our moments of panic, exuberance or exhaustion, our joy over the development of meaningful relationships and our excitement when we are 'struck' by something, and the despair, resignation or satisfaction that accompany writing up. Yet these emotions are often dismissed in a number of curious ways: frequently left out of anthropological research methods courses, frequently edited out of ethnographic texts, admonished when they slip into PhD seminars, in general confined to personal fieldnotes, at times turned into jokes or asides, and at other times treated with uncertainty, embarrassment or silence. How has this state of affairs come about? Is it only due to anthropology's over-reliance on the Western academy and its Enlightenment split between knowing and feeling, turning emotions into the dangerous 'other' of knowledge? Or does it go beyond the question of hierarchies of knowledge and probe into the regulatory regimes of the anthropological community itself, turning emotions into an object of discipline? The contributions to this issue of the Anthropology Matters Journal all circle around this underlying and complex question: What is the function of emotions in the socio-cultural anthropological research process?

\section{Emotions as epistemological and disciplinary regimes}

Do emotions, as Rachel Irwin argues, operate as 'anthropology's taboo'? Or do they, as Celayne Heaton Shrestha suggests, form the strategic shifts of the archetypal anthropological apprenticeship journey, from fieldwork and powerlessness to power and distancing? In either case, emotions seem to have a surprisingly important function in the processes through which novice researchers are disciplined into anthropology. In her article 'Culture shock: negotiating feelings in the field', Irwin argues that the pervasive and tacit impact of culture shock on fieldworkers' experiences and research has never been adequately acknowledged and addressed within anthropology. She provides illustrative examples from her own experience in western Kenya that, I think, any fieldworker who has crossed cultural boundaries will recognise. In sum, she argues that the silence that surrounds these emotional experiences is so pressing that it amounts to a taboo that functions 'to protect the local consensus on how the world is organised' (p. 10) within anthropology. It is not hard to see how it feeds into a certain consensus - a complicated one, but readily 
recognisable, I think, to anyone who has been through anthropology $\mathrm{PhD}$ seminars and a PhD viva — on how 'emotionally detached' knowledge should be produced, all the while hiding from view the important emotional shocks, engagements and disengagements that have actually happened.

Celayne Heaton Shrestha takes a different view. In her article 'Emotional apprenticeships: reflection on the role of academic practice in the construction of "the field"', she argues that the emotional engagements that take place are not exactly suppressed in the anthropology department, but rather subtly and strategically formed and transformed. She plots the journey of the novice anthropologist, drawing on examples from her own experience in Nepal and London, from a position of vulnerability and powerlessness in the field, to a growing feeling of power and distance as she returned to her anthropological institution. This shifting emotional emphasis was encouraged by the way post-field training is set up, implicitly (and sometimes explicitly) legitimising the memory and cultivation of some emotions while delegitimising others, thus reinforcing hierarchy and a certain process of Othering.

Then again, Kate Woodthorpe takes a third and different view on what the relationship between emotions and the methodological (and disciplinary) processes of anthropology might be. In her article 'My life after death: connecting the field, the findings and the feelings', she traces her own rites of passage as she sought to understand experiences in a contemporary cemetery landscape in East London. Her emotional involvement changed from being anxiously detached yet overly caught up in the topic of death, to a deeper process of insight about what the topic meant to her, and how her emotional state should be seen in association with the data that she was collecting in the cemetery. From then on she was able to use her own anxiety as a key empathetic strength in the analytical process.

These first three articles form what can be loosely called the analytical springboard of the collection. They take us through three different perspectives on what the relationship(s) between emotions and anthropology's epistemological and disciplinary regimes might be: at times emotions are suppressed in the anthropology department and function as a collective taboo, as Irwin shows; at times their emphasis is strategically changed, as Shrestha shows; and at times they are brought about because of academic exchanges that acknowledge their importance, and they become key tools in our understanding, as Woodthorpe shows. All three authors, however, have one thing in common: they all choose to focus on the importance of the anthropological methodology of fieldwork, reiterating once again that we need to explore more fully why emotions, which are an inextricable part of this method, have not been given greater attention within anthropology, and how this avoidance seems to be intimately linked to some of the less noble aspects of our epistemological and disciplinary regimes - including disavowal of culture shock, and ingrained processes of othering.

\section{Emotions and relationships to significant others}

The next articles move on to examine the function of emotions as openings to significant others - whether our parents, partners, or key 'informants' - during the research process. What are the implications when some researchers acknowledge that emotions became intimately bound up in their relationships in the field in a way that functioned to challenge their understanding of what the 'field' was, driving them to 
deeper questions about their previous distinctions and knowledge systems - nowhere becoming more obvious than when you marry 'in the field', as Anna Cristina Pertierra did, or when you follow in your father's footsteps 'to the field', as Chi-Chi Undie did? Again, emotions seem to cut to the core of anthropological epistemological assumptions, raising complicated questions about how exactly emotions shape our data gathering, sorting, analysis, and ethnographic conclusions, let alone which deepseated emotional outlooks are baked into the roles we assume on the way.

In her article 'Anthropology that warms your heart: on being a bride in the field', Pertierra presents a vivid account of the events and thoughts and emotions that surrounded her wedding in Santiago, Cuba; her fieldsite. Most strikingly, she experienced that suddenly her object of study-namely the Cuban women's everyday strategies of locating and securing basic household supplies-became issues that mattered to her on a personal level, as she went through the tumultuous tasks of trying to assemble items for her wedding. Her story illustrates that the role of 'participant observer' may pre-suppose more emotional distanciations than we care to admit; it was not until Pertierra momentarily dropped this role that she gained a greater understanding of the emotional processes of the everyday lives of the Cubans around her.

Chi-Chi Undie, like Pertierra, had a significant personal relationship woven into her field research. In her article 'My father's daughter: becoming a "real" anthropologist among the Ubang of Southeast Nigeria', she describes how she found herself having to negotiate complex relationships and expectations when she followed in the footsteps of her anthropologist father. Most complex of all, perhaps, were the expectations that she placed on herself, knowing that she would like to produce research as recognised as her father's on the Igbo, yet also gradually realising that her methods and the viewpoints she brought out-focusing on the Ubang women who collaborated with her on her research-were in fact quite different from his. Her description brings out clearly an aspect of her research process that is in some way inherent in all anthropological research processes, namely a negotiated sorting out of personal connections and differentiations. We all have someone we write for (regardless of whether they will read what we write), someone we would like to gain recognition from - whether it is our partners, our 'informants', our supervisors, or our parents. As Undie demonstrates, if this striving for recognition and connection is acknowledged and reflected upon during the research process, it can in fact form the basis of a more mature personal differentiation, leading to greater intellectual and emotional integrity when the final task of presenting one's research findings arrives.

Anne Monchamp, in 'Encountering emotions in the field: an X marks the spot', extends this discussion of the relationship between emotions, relationships and research processes into a broader exploration of the role that emotions can play in building relationships with one's 'subjects of study'. She starts her account of her fieldwork in an Australian Central Desert community by describing a conversation that occurred one day when a woman asked her whether she 'had a man', and Monchamp decided to give an honest answer: a month ago she had a man, now she didn't. The various stories that the women shared with her after this moment of personal exposure became an important part of their relationships.

The three articles presented by Pertierra, Undie and Monchamp all bring out how our relationships with significant others in our lives, who are apparently 'separate' from our research site, can still have a subtle yet striking effect on our research process. 
Anthropologists in the field will have emotional involvements that extend into the field and beyond it; we will fall in love in the field, exchange emails with our family, carry painful memories of broken-off relationships with us, or simply seek the recognition of someone who is important to us. These emotional aspects of the research process are often hidden away afterwards. However, Pertierra, Undie and Monchamp show that these emotional engagements and relationships can in fact strengthen and revitalise our research, if we are prepared - as they have been-to have the courage to simply acknowledge the situation.

\section{Emotions as method and object of study}

In the next group of articles, the authors-Dutton, Mossière, Tassi and Charlesworth-present situations where emotions form a key aspect of both their object of study as well as their method. In 'Eye-glazing and the anthropology of religion: the positive and negative aspects of experiencing and not understanding an emotional phenomenon in religious studies research', Edward Croft Dutton provides an intriguing description of the phenomenon of 'eye-glazing'. Eye-glazing is a glazed, withdrawn look that Dutton encountered a few times in his research into Evangelical groups in the United Kingdom, and that left him with a feeling of having brushed up against a powerful and haunting phenomenon that he was not able to fully or straightforwardly explain within an anthropological academic framework. Indeed, the emotional 'shock' of encountering this experience left him with a deeper fascination for his subject and a strong motivation to continue his research, as well as a deeper appreciation of the ineffable nature of intense religious experiences and the complexity of trying to capture them through a research method.

Géraldine Mossière's article, 'Sharing in ritual effervescence: emotions and empathy in fieldwork', also describes research on a religious group, namely a Pentecostal church in Montreal, Canada. She too, like Dutton, found herself grappling with questions of how to engage with and understand religious experiences when she herself had not 'experienced' the experiences. While attending the church services and observing the 'ritual effervescence' produced by the singing, clapping and preaching, she gradually adopted a 'liminal' research position: she would outwardly, to some degree, participate, while inwardly paying close attention to the emotional effects that the ritual elements were having on her, without censoring her own emotions. She argues that this liminal position allowed her to attain an important measure of empathy with the believers; indeed, she eventually found that she too experienced some states of 'deep joy and grace' (p. 7). This, however, always existed in tension with her awareness that she disagreed with the overall message that was being presented, and at times she was left feeling irritated, shaken and nervous.

The emotional tone of Nico Tassi's research is slightly different. Like Dutton and Mossière, he describes an intensely emotional event with religious undertones, namely a festival in La Paz, Bolivia. However, unlike Dutton and Mossière, Tassi does not focus primarily on the religious aspect of people's experiences in the festival, but rather on the multi-layered experiences of corporeality, materiality, and attraction that the festival brings out. In his article, 'The politics and aesthetics of attraction in the Gran Poder festival: reflections on a "methodology of affect", he traces the 'unacknowledged zone' of shared pleasure that people from different social classes encounter when they come together in the festival's dancing, and, in the end, he notices that the sensorial experience of the music has 'gotten into him' too. 
With Simon J. Charlesworth's article, we move from a scene of dancing and attraction to one of incoherency, invisibility and depression. In his article, 'Reflections on violence and suicide in South Yorkshire: (Dis-)United Kingdom', Charlesworth closely examines the mental, emotional and corporal processes that constitute the lives of the working class in South Yorkshire. He shows how the strains of not receiving recognition, experiencing oneself-based on other's reactions - to be either invisible or repulsive in public places, not being able to spend money in order to 'appear' in public, and living with constant financial worry, together lead, in Bourdieu's term, to a 'destructuring of existence' (p. 9). This destructuring brings with it a desperate indifference: an inhuman attempt not to care, severing connections to others and to oneself. Charlesworth frames his article with the harrowing example of three local suicides that took place within a month: a self-inflicted violence that all too understandably mirrors the larger structures of violence-processes of negation and atomisation - that the working class in the current British economy live within.

The emotional shifts between the articles by Dutton, Mossière, Tassi and Charlesworth are dramatic and captivating. They have each sensed that the emotional quality of their object of study was key to an insight into it, and they have focused their method and writing on capturing some of the complexities and nuances of the emotional processes, techniques, spaces, experiences and states involved. They do this through negotiating a difficult balance between not censoring their own emotions and the various states that are triggered in them during the research process, while at the same time seeking to respond to these feelings and states in a way that will lead them to a greater understanding of the state of the other. To sum up, Tassi argues that this inclination to engage with things that demand to be felt can potentially have a revitalising effect on the disciplinary language of anthropology, perhaps adding some more richness to the logical and discursive mode of knowledge that is currently granted superiority. Tassi terms his approach a 'methodology of affect', and the challenge, he suggests, is still one of allowing oneself to be 'affected' by the other.

\section{Emotional shifts and anthropology's public image}

The final article of this collection invites us to look towards the future of our discipline. Tod Hartman, in his article 'Beyond Sontag as a reader of Lévi-Strauss: "anthropologist as hero", discusses the shifts that have occurred in the image of the 'heroic' anthropologist. The heroism of Lévi-Strauss - 'setting out' into the unknown, beset by doubt and questioning, undergoing a cathartic journey, and returning with knowledge and artefacts - still resonates strongly within the anthropological imagination and the public perception of anthropology. However, new forms of heroism have recently been added to the fold. Hartman offers a provocative discussion of activist anthropology, in which he raises the question of whether the emotional appeal of human rights activism will serve to water down, or even remove, the selfcritical questioning of the engaged anthropologists as well as the possibility of placing the resulting work under critique. He also discusses the emerging recognition of 'anthropology at home', noting that here too the emotional dynamics between the researcher and the researched has been altered. When conducting anthropology at home, anthropologists are required to exhibit 'heroic honesty' and a much higher level of accountability towards their subjects of study. In conclusion, Hartman notes that the public perception of anthropology has not caught up with the changes that have taken place within anthropology, and that in the face of threats of funding cuts, we 
would do well to reinvigorate our public image. An important part of this move may be to direct attention to the new forms of heroism within anthropology, with their attendant emotional shifts between researcher and researched, and their willingness to engage head-on with the world today.

\section{Concluding remarks}

Let us return to the opening question: What is the function of emotions in the sociocultural anthropological research process? From this brief overview of the eleven articles included in the journal issue, it becomes apparent that although emotions have often been dismissed and edited out of the public texts of anthropology, they have nevertheless been given several 'silent' functions, including in such core processes as the way in which we produce knowledge, the way in which we negotiate the right to be included in our discipline, the way in which the other becomes The Other, and the way in which we are perceived by the public. We might do well to examine emotions more closely and in a wider range of fora than has been done up until now.

In sum, therefore, this journal issue aims to contribute towards a broader and more open discussion on the function of emotions. The collection of articles draws out several and different implications of the 'emotion work' that anthropologists live with, build on, think about, cover over, attempt to express, negotiate, and manoeuvre within and around in various ways. The authors attempt to address the epistemological implications of their emotions with some integrity, and, more broadly, to move the state of play in this field forward. They bring to life those instances where emotions are deeply integrated into one's research, but where for some reason it is difficult to know how to deal with this. They each sketch out their own changing strategies - in the moment and subsequently - and in this way collectively form a journal issue that can be read at two levels: first, as a provocative questioning of anthropology's epistemological assumptions and disciplinary boundaries; and second, as a sort of research manual on fielding emotions, based not on the orthodoxies that more often than not are administered in anthropology methods courses ('just make sure you don't go native!'), but rather on the unresolvable real-life situations presented here that are still a part of the authors' lives, and that they have had to deal with in tentative, vulnerable, amusing and innovative ways. Perhaps it is precisely in this area that we will find processes and means to bolster revitalisation in our discipline through the next generation.

\section{About the author}

Ingie Hovland completed a $\mathrm{PhD}$ in Social Anthropology at SOAS (University of London) in 2006, entitled Distance Destroys and Kills: An Anthropological Inquiry into the Nature of Faith in a Lutheran Norwegian Missionary Society. Her research interests include religion, sincerity, gender, historical anthropology, and ethnographic method, and she is currently teaching part-time at SOAS on Women, Men and Christianity. She is the Editor of the Anthropology Matters Journal and is happy to receive submissions to the journal for review-she can be contacted at ingiehovland@yahoo.co.uk 